IZA DP No. 314

\title{
Age-Differentiated QALY Losses
}

Bernard M.S. van Praag

Ada Ferrer-i-Carbonell

J une 2001 


\title{
Age-Differentiated QALY Losses
}

\author{
Bernard M.S. van Praag \\ University of Amsterdam, Tinbergen Institute and IZA, Bonn
}

Ada Ferrer-i-Carbonell

University of Amsterdam and Tinbergen Institute

\author{
Discussion Paper No. 314 \\ June 2001
}

\author{
IZA \\ P.O. Box 7240 \\ D-53072 Bonn \\ Germany \\ Tel.: +49-228-3894-0 \\ Fax: +49-228-3894-210 \\ Email: iza@iza.org
}

This Discussion Paper is issued within the framework of IZA's research area General Labor Economics. Any opinions expressed here are those of the author(s) and not those of the institute. Research disseminated by IZA may include views on policy, but the institute itself takes no institutional policy positions.

The Institute for the Study of Labor (IZA) in Bonn is a local and virtual international research center and a place of communication between science, politics and business. IZA is an independent, nonprofit limited liability company (Gesellschaft mit beschränkter Haftung) supported by the Deutsche Post AG. The center is associated with the University of Bonn and offers a stimulating research environment through its research networks, research support, and visitors and doctoral programs. IZA engages in (i) original and internationally competitive research in all fields of labor economics, (ii) development of policy concepts, and (iii) dissemination of research results and concepts to the interested public. The current research program deals with (1) mobility and flexibility of labor markets, (2) internationalization of labor markets and European integration, (3) the welfare state and labor markets, (4) labor markets in transition, (5) the future of work, (6) project evaluation and (7) general labor economics.

IZA Discussion Papers often represent preliminary work and are circulated to encourage discussion. Citation of such a paper should account for its provisional character. 
IZA Discussion Paper No. 314

June 2001

\section{ABSTRACT}

\section{Age-Differentiated QALY Losses}

In this paper we evaluate the QALY losses, which are linked to the prevalence of specific chronic illnesses and impediments. The analysis is based on the individual self-rating health satisfaction question asked in the British Household Panel Survey data set. Our method is a refinement of the method of Cutler and Robertson (1997). First, we use more information regarding the relationship between the latent variable 'health' and its evaluation into observable QALY's. Second, we allow the QALY loss caused by a illnesses to depend on age. For instance, according to our approach a 30 years old male suffering from diabetes would experience a QALY loss of 0.135 while this would be only 0.084 , if the male is 60 years old.

JEL codes: I10, I12

Keywords: Chronic diseases, health satisfaction, QALY loss, QALY weight

Bernard M.S. van Praag

Faculty of Economics and Econometrics

University of Amsterdam

Roetersstraat 11

1018 WB Amsterdam

The Netherlands

Tel.: +31 2052560 18/15

Fax: +31205256013

Email: bvpraag@fee.uva.nl. 


\section{Introduction}

When we talk about health losses due to a chronic illness or a physical impediment, two questions are relevant: what is the severity of the loss per time period and how long will the loss last? The Quality Adjusted Life Year (QALY) is a well - known concept, which measures the average health during one year on a 0 to 1 - scale (for surveys see Torrance, 1986, and Dolan, 2000). In this paper, we focus on an assessment of the QALY difference between being with or without an illness or impediment. For chronic diseases the duration is permanent by definition.

There is no uniformity on how health should be measured. There are four main methods to measure individual's health, viz., expert rating, individual self-rating, standard gamble, and time-trade-off (see Torrance, 1986).In the first approach the health of an individual is evaluated by asking the opinion of experts such as medical doctors. In the second approach individuals themselves are asked to rate their own health status on a discrete ladder scale. In the third approach respondents are offered a (hypothetical) choice between their present health situation and a treatment with two possible outcomes associated with two probabilities. In the fourth method patients have to make a choice between the present health status for $\mathrm{T}$ years or perfect health for $(\mathrm{T}-\mathrm{K})$ years.

The four methods yield different outcomes. The QALY definition depends on the method used. This paper identifies the QALY loss caused by specific illnesses and impediments on the basis of individual self-rating of own health. This choice has already been made before by, for example, Cutler and Robertson (1997) when analysing US data and by Groot (2000), who analysed British data in a similar way. These authors implicitly assume that the relationship between a latent variable health status $H S$ and the corresponding evaluation of it in terms of QALY is linear over the relevant region. We refine this relation by applying an empirically estimated concave spline function. Doing so the QALY loss is no longer linearly proportional with the loss in $H S$. Furthermore, we extend their previous work by offering a method in which the evaluation of health changes due to an illness ${ }^{1}$ are allowed to depend on age. We do that by including an interaction term between age and illness. We see that for certain illnesses the impact on

\footnotetext{
${ }^{1}$ In the following we shall speak of illnesses instead of 'illnesses and impediments'.
} 
the individuals subjective health perception depends on their age. We use the panel data set of the British Household Panel survey (BHPS) for the empirical analysis.

The paper is structured as follows. We discuss the model in section 2 . We present the estimation results and the data in section 3. We discuss the results and draw some conclusions in section 4 .

\section{The model}

We measure health by means of the following health satisfaction question

\section{How dissatisfied or satisfied are you with your health?}

This question has been posed in the BHPS since 1996. We call the answer to this question the individual's Health Satisfaction $(H)$. In the BHPS individuals are asked to restrict their answers between 1 and 7, where 1 stands for 'very dissatisfied' and 7 for 'very satisfied'. Let $H S$ (Health) be the continuous latent variable underlying health satisfaction, then we assume

$$
H S_{n t}=C_{t}+\beta X_{n t}+\gamma^{\prime} d_{n t}+\varsigma \bar{X}+\varepsilon_{n t}+v_{n}
$$

where $n$ stands for the individual and t for time. The dependent variable Health $(H S)$ is not observed and therefore we can only estimate equation (1) by using the discontinuous variable $H$. We estimate (1) by ordered probit. The vector $X_{n t}$ includes various explanatory objective variables such as income and age. The vector $d_{n t}$ is a dummy vector, where the $j^{\text {th }}$ component equals one if the respondent suffers from the illness $j$ and equals zero otherwise. The error term $\varepsilon_{n t}$ is assumed to be $\mathrm{N}(0,1)$-distributed as usual in ordered probit analysis. We allow for individual random effects $v_{n}$, which are constant across time but differ across individuals. We also include fix time effects, $C_{t}$. Furthermore, we incorporate some of the explanatory variables $(X)$ not only as their yearly value but also as the average over the three years $\left(\bar{X}_{n}\right)$. Mundlak (1978) proposes the same specification, where he interprets the mean of $X$ as picking up the correlation 
between the observed individual characteristics $\left(X_{n t}\right)$ and the individual unobservable random-effects $\left(\mathrm{O}_{n}\right)$. As regards content, an alternative explanation lies at hand. As explained in Van Praag et al. (2000), we may distinguish between shock and level effects. We have

$$
\beta X_{n t}+\varsigma \bar{X}_{n}=\beta\left(X_{n t}-\overline{X_{n}}\right)+(\beta+\varsigma) \overline{X_{n}}
$$

The deviation from the mean, i.e. $(X-\bar{X})$, stands for the effect of an incidental change from the mean, while the term $\bar{X}$ gives the long- term effect in the steady state. We call the first term the shock effect and the second the level effect. For income, this distinction yields the permanent and transitory income concepts introduced by Friedman (1957). The two interpretations do not exclude each other but are complimentary. We distinguish in the estimation procedure between shock and level effects in order to get better estimates of the chronic health effects.

In estimating (1) with ordered probit, we estimate the usual intercepts $\mu_{1, \ldots}, \mu_{6}$, which link the latent variable $H S$ to the discrete response categories $\left(H_{i}\right)$ with $i=1, \ldots, 7$. There holds

$$
\text { if } H=i \quad \Leftrightarrow \quad \mu_{i-1}<H S \leq \mu_{i}
$$

where $\mu_{0}=-\infty$ and $\mu_{7}=+\infty$. Equation (1) is similar to the equation that has been estimated by Cutler and Richardson (1997) and by Groot (2000). We want to extend on their work in two ways. First, we include in (1) some interaction terms between illnesses and age. In that way we are able to capture the interaction between specific illnesses and age. Cutler and Richardson (1997) introduced a method for calculating QALY weights for illnesses by using a health satisfaction equation such as (1). We call their approach the C-R method. Following the C-R method, the QALY loss for an illness $j$ equals $\left(\gamma_{j} /\left(\mu_{6}-\mu_{l}\right)\right)$ This procedure is tantamount to assuming a linear relationship between the latent variable $H S$ on the interval $\left(\mu_{1}, \mu_{6}\right)$ and the corresponding QALY evaluation on the interval $(0,1)$. The C-R method identifies the upper and lower intercept with the border line of excellent 
health (QALY =1) and the status of near death (QALY =0) respectively. In other words, they equal $H S \leq \mu_{1}$ with a QALY of 0 and $H S \geq \mu_{6}$ with a QALY of 1 . We suggest to refine the $\mathrm{CR}$ method by using more information on the relationship between $H S$ and $H$. For that, we use the other intercept points $\left.\boldsymbol{\mu}_{2}, \ldots, \boldsymbol{\mu}_{5}\right)$ as well. This is the second innovation of this paper. We propose the following identification rule for our seven categories that is

$\begin{array}{llllrl}\text { if } & H S & \leq \mu_{I} & \Leftrightarrow & \text { QALY } \leq(1.5-1) / 7 \\ \text { if } & \mu_{l}<H S \leq \mu_{2} & \Leftrightarrow & (1.5-1) / 7<\text { QALY } \leq(2.5-1) / 7 \\ \ldots \ldots & & & \\ \text { if } & \mu_{6} & <H S & \Leftrightarrow & \end{array}$

Division by 7 and subtraction of 1 is applied to standardise the QALY values between 0 and 1 as usual in the literature. The identification rule assumes that respondents answer 1 $(H=1)$ if their health quality is between 1 and 1.5 . If their health quality is 1.6 , then respondents round off upwards and their answer is $2(H=2)$.

This approximation of the function QALY $=\mathrm{QALY}(H S)$ is no longer linear on the interval $\left(\mu_{1}, \mu_{6}\right)$, except if the $\mu$ 's are equidistant. In our approach, the relationship between $H S$ and QALY is approximated by a spline function with six nodes (see fig.1). Obviously ,the tails cannot be approximated by a straight line. An exponential curve might be a probable candidate for the approximation of the tails. For simplification, we approximate an expected value of $H S$ smaller than $\mu_{l}$ by a QALY of 0 . We do not find any expected value of $H S$ larger than $\mu_{6}$. 


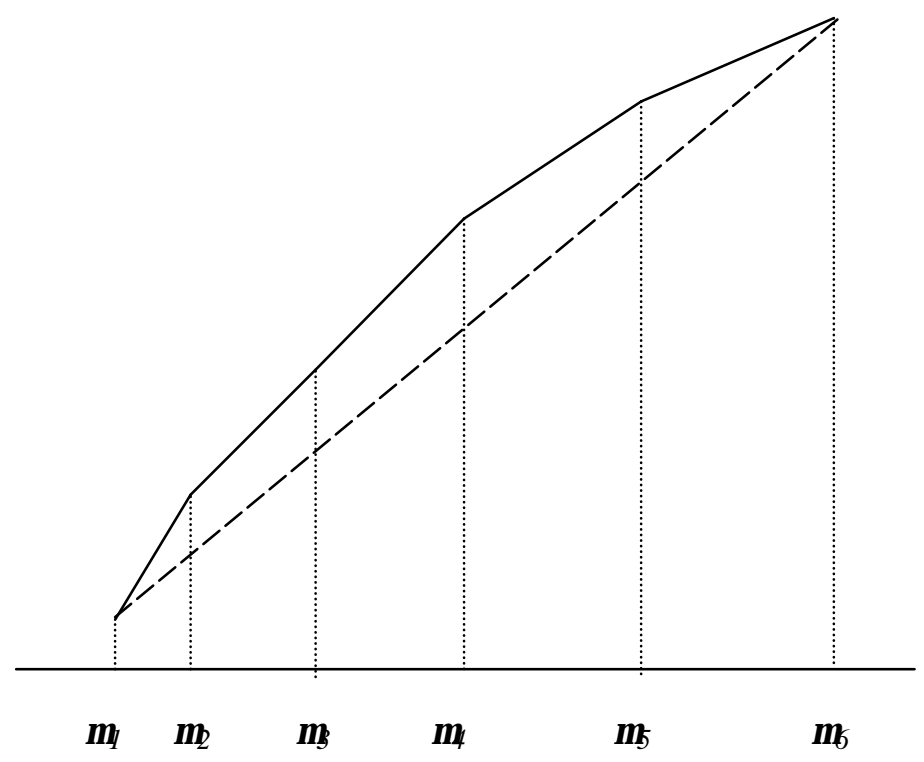

Figure 1. The relation between $H S$ and QALY approximated by a spline function and by linear interpolation.

We see from figure 1 that the curve is concave in $H S$. This is caused by the increasing distances between the intercept points.

Now we like to define the analogue to the Cutler- Robertson QALY weight. In the case of a linear health function a negative change in HS implies a QALY loss in health, which does not depend on the point of departure. If the QALY evaluation was 1.0 to begin with, a QALY loss of 0.2 assigned to a specific illness would imply a decline to 0.8 and if the starting position was 0.7 it would imply a fall to 0.5 . However, in our case the loss in health depends on the change in $H S$ and on the point of departure. We make a difference between absolute and relative QALY losses. We define the absolute QALY loss caused by a specific illness $j$, which can be compared to the QALY weights in the CR approach, as

$$
Q A L Y(H \hat{S}(X))-Q A L Y\left(H \hat{S}\left(X+d_{j}(X)\right)\right)
$$


where $H \hat{S}$ stands for the expected health status without illness, which is calculated for different values of $\mathrm{X}$, and where $d_{j}(X)$ stands for the effect of the illness $j$ on a person of type $X$. Hence we define the QALY of a healthy individual with personal characteristics $X$ as $H \hat{S}(X)$, where the illness dummies are all set equal to zero. We use eq.(5) in order to calculate the QALY loss, where the function is the spline function, depicted in fig.1. The relative QALY loss, is then defined as,

$$
\frac{Q A L Y(H \hat{S}(X))-Q A L Y\left(H \hat{S}\left(X+d_{j}(X)\right)\right)}{Q A L Y(H \hat{S}(X))}
$$

\section{Data and estimation results.}

\subsection{The data.}

For the empirical analysis, we make use of the British Household Panel Survey (BHPS). The BHPS is a comprehensive household survey covering about 10,000 individuals belonging to more than 5000 British households. The BHPS is described in Taylor et al. (1999). We consider waves six to eight corresponding to 1996, 1997, and 1998 respectively. The reason for this restriction is that the health satisfaction question is only asked after wave 5. The survey includes a catalogue of various illnesses and impediments, where the respondents have to answer whether they suffer from it or not. There is also a host of socio-economic and demographic variables referring to the individual and the household, e.g. age, children, education, and household income.

\subsection{Estimation}

Table 1 presents the estimation results for different specifications of equation (1). First, we estimate health satisfaction $(H)$ by various socio-economic and demographic variables such as age, income, education, family size, and employment status. Second, we also include dummies for illnesses. Third, we add interaction terms between the illnesses and age in order to make the illness effects age - dependent. The last specification is, to our best knowledge, estimated for the first time. 
Let us start with the simplest explanation where no information about the prevalence of diseases is used. The first two columns of table 1 show the results. As expected, health falls monotonically with age (see also Deaton and Paxson, 1998). Health satisfaction is positively and significantly correlated with the mean of income, i.e., with permanent income. The positive correlation between income and health has been extensively discussed in the literature (see, e.g., Smith, 1994; Deaton and Paxson, 1998). Incidental fluctuations in income, i.e. the shock effects, do not seem to affect health. Males are slightly more satisfied with their health than females. The coefficient for education is negative and non-significant. The negative correlation between education and health satisfaction has also been found by Groot (2000) and Kerkhofs and Lindeboom (1995). We also notice that, health-wise, having children seems to be a mixed blessing. There seems to be an optimum number between one and two.

The results for the second specification are shown in the third and fourth columns of table 1. The quadratic specification of age shows that age has now a positive effect on health from the age of 29.5 years old onward. Thus, the inclusion of the dummy for illnesses changes the age coefficient from negative to positive. This may be explained by the fact that most illnesses are correlated with age, where the variable age in the first specification is picking up the effect of the illnesses. Gender effects are now nonsignificant. Education becomes significant and is still negative. The children effect persists but becomes non-significant at the 5\% level. The other coefficients do not change with the introduction of dummy diseases. The disease coefficients are all significant and negative. The values found are roughly comparable with Groot's estimates on only one wave of the same data set. Using this, we can derive a hierarchy of diseases according to the magnitude of their effects on individual health satisfaction.

The results of the third specification are presented in the fifth and six columns of table 1. By including interaction terms between diseases and age, we can analyse whether the impact of the illness on health satisfaction is age-dependent. This may have several reasons. One, the objective degree of severity of an illness may vary with age. This is the case for 'chest and breath problems`. Two ,even if the illness is becoming objectively more severe with age, the individual may subjectively perceive it differently. The reasons can be diverse: people may adapt to an illness, it may be that individuals require less 
from their body than when they were young ,e.g. in sports, and it may be that when growing older they get other ailments as well, such that their original illness becomes one of several complaints. These reasons could be the explanation for the positive age coefficients found for 'difficulty in hearing', 'heart and blood problems', 'problems with the stomach, liver, and kidneys', 'diabetes', and 'anxiety, depression or bad nerves'. For some impediments and illnesses, we did not find a marked age-dependency and thus we did not include an interaction term with age. Similarly, the dummy coefficient found for 'chest and breath problems' becomes non-significant when we include an interaction term with age. Figure 2 displays the age pattern for various illnesses, i.e. $d_{j}+d_{j} \ln$ age . We see that QALY losses diminish with age except for the 'chest and breath problems'. Finally, we notice that the variances of the individual random effects are fairly large and represent about $50 \%$ of the total unobservable effects. 


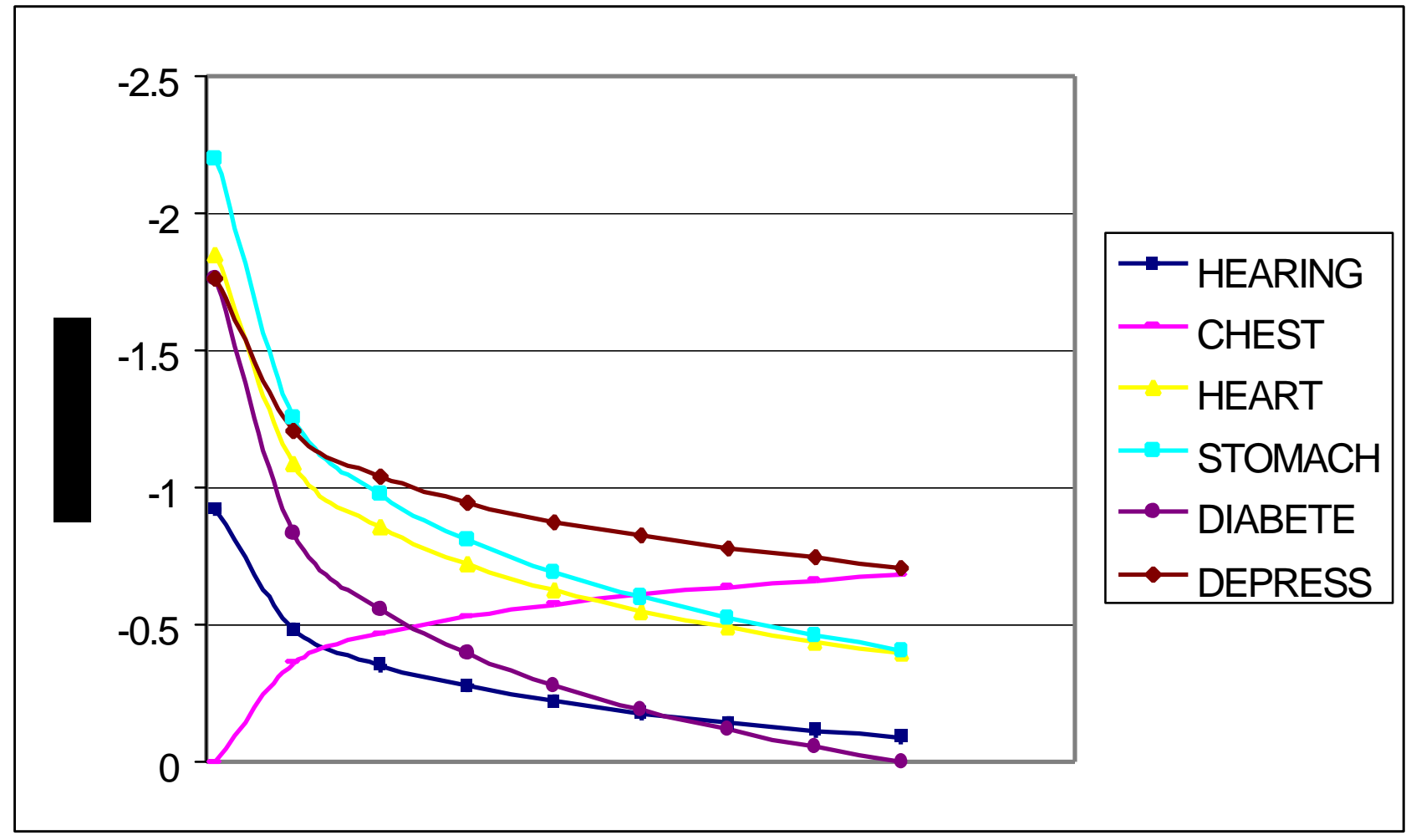

Figure 2: Age pattern of QALY weights for various illnesses and impediments 
Table 1: Health Satisfaction Probit Equations

\begin{tabular}{|c|c|c|c|c|c|c|}
\hline & Coeff. & Std.Err. & Coeff. & Std.Err. & Coeff. & Std.Err. \\
\hline Intercept term & 4.308 & 4.671 & 7.039 & 9.022 & 5.700 & 7.149 \\
\hline Time Fix Effect 1996, wave 6 & -0.096 & -5.944 & -0.138 & -8.550 & -0.139 & -8.646 \\
\hline Time Fix Effect 1997, wave 7 & -0.038 & -2.403 & -0.057 & -3.654 & -0.057 & -3.659 \\
\hline \multicolumn{7}{|l|}{$\mathrm{X}$} \\
\hline Ln (age) & -1.289 & -2.472 & -2.419 & -5.436 & -1.598 & -3.500 \\
\hline Ln2 (age) & 0.131 & 1.829 & 0.357 & 5.807 & 0.235 & 3.714 \\
\hline Minimum & 137.362 & & 29.642 & & 29.879 & \\
\hline Ln (income last month) & -0.010 & -0.654 & -0.019 & -1.213 & -0.020 & -1.294 \\
\hline Ln (children +1) & 0.176 & 2.005 & 0.097 & 1.163 & 0.092 & 1.101 \\
\hline Ln2 (children +1) & -0.162 & -2.671 & -0.102 & -1.901 & -0.101 & -1.866 \\
\hline Махітит & 1.726 & & 1.605 & & 1.578 & \\
\hline Male & 0.103 & 3.812 & -0.011 & -0.463 & -0.012 & -0.522 \\
\hline Ln (years Education) & -0.034 & -1.065 & -0.064 & -2.268 & -0.067 & -2.366 \\
\hline Missing Education & -0.158 & -1.871 & -0.197 & -2.396 & -0.209 & -2.532 \\
\hline Living together? & 0.016 & 0.565 & -0.015 & -0.586 & -0.013 & -0.537 \\
\hline \multicolumn{7}{|l|}{ Illness Dummy } \\
\hline Arms, legs, hands, feet, back, or neck & & & -0.649 & -31.950 & -0.649 & -31.935 \\
\hline Difficulty in Seeing & & & -0.252 & -6.669 & -0.262 & -6.888 \\
\hline Difficulty in Hearing & & & -0.156 & -4.569 & -0.923 & -2.484 \\
\hline Skin conditions/allergies & & & -0.138 & -4.704 & -0.142 & -4.809 \\
\hline Chest/breathing problems & & & -0.583 & -21.987 & & \\
\hline Heart/blood problems & & & -0.511 & -19.100 & -1.853 & -5.314 \\
\hline Stomach/liver/kidneys & & & -0.608 & -19.227 & -2.199 & -6.671 \\
\hline Diabetes & & & -0.673 & -10.475 & -2.293 & -2.847 \\
\hline Anxiety, depression or bad nerves & & & -0.852 & -28.138 & -1.760 & -5.906 \\
\hline Alcohol or drug related problems & & & -0.948 & -6.754 & -0.889 & -6.327 \\
\hline Epilepsy & & & -0.649 & -6.118 & -0.654 & -6.179 \\
\hline Migraine or frequent headaches & & & -0.270 & -8.898 & -0.263 & -8.623 \\
\hline Other health problems & & & -0.787 & -23.594 & -1.436 & -4.548 \\
\hline \multicolumn{7}{|l|}{ Illness Dummy*Age } \\
\hline Difficulty in Hearing $* \ln ($ age $)$ & & & & & 0.190 & 2.093 \\
\hline Chest/breathing problems $* \ln ($ age $)$ & & & & & -0.156 & -22.730 \\
\hline Heart/blood problems $* \ln ($ age $)$ & & & & & 0.333 & 3.908 \\
\hline Stomach/liver/kidneys $* \ln ($ age $)$ & & & & & 0.409 & 4.924 \\
\hline Diabetes $* \ln ($ age $)$ & & & & & 0.401 & 2.048 \\
\hline Anxiety, depression or nerves $* \ln ($ age $)$ & & & & & 0.239 & 3.104 \\
\hline Others $* \ln ($ age $)$ & & & & & 0.167 & 2.079 \\
\hline
\end{tabular}




\begin{tabular}{lcccccc}
\hline $\bar{X}$ & & & & & & \\
Mean (Ln(income last month)) & 0.194 & 7.928 & 0.081 & 3.579 & 0.082 & 3.620 \\
Mean (Ln(children +1)) & 0.128 & 1.948 & 0.090 & 1.411 & 0.091 & 1.425 \\
& & & & & & \\
$\mu^{*}$ & & & & & & \\
$\mu_{2}$ & 0.523 & 38.851 & 0.543 & 39.379 & 0.543 & 39.335 \\
$\mu_{3}$ & 1.210 & 72.900 & 1.253 & 74.478 & 1.254 & 74.518 \\
$\mu_{4}$ & 1.923 & 106.559 & 1.981 & 108.520 & 1.984 & 108.596 \\
$\mu_{5}$ & 2.794 & 145.391 & 2.855 & 147.111 & 2.859 & 147.273 \\
$\mu_{6}$ & 4.050 & 193.934 & 4.085 & 192.157 & 4.090 & 192.282 \\
& & & & & & \\
$\sigma\left(v_{I}\right)$ (individual random effect) & 1.264 & 97.002 & 0.994 & 83.229 & 0.992 & 83.026 \\
& & & & & & \\
Log Likelihood & -48702 & & -46719 & & -46685 & \\
Numb Individuals & 12033 & & 12033 & & 12033 & \\
Numb Observations & 29979 & & 29979 & & 29979 & \\
Chi-Squared & 7863.657 & & 4510.775 & & 4484.208 & \\
\hline
\end{tabular}

$* \mu_{l}$ is standardised at 0 . 
Next, we present in table 2 the absolute and relative QALY losses and weights for all illnesses included in the BHPS for a male of 30 years old and for a male of 60 . For these calculations, we use the third specification of table (1) and equations (4), (5), and (6). As a reference group we take males in 1996, living in partnership, with an income of U.K. $£ 1900$ per month, two children, and 10 years of education ${ }^{2}$. Table 2 also presents the QALY weights when we apply the C-R approach to the second specification of table 1. Using the third specification and taking age at the sample average gives rise to similar results, which we do not present in table 2 . Table 2 shows, for example, that an individual of 30 years old who suffers from diabetes has a QALY loss of 0.135 in a $(0,1)$ scale, while a man of 60 would have a loss of only 0.084 . Table 2 shows that for all diseases except for 'chest and breath problems', the absolute and relative QALY losses are equal or bigger for a 30 years old man than for a 60 years old man.

Table 2: QALY losses due to various diseases

\begin{tabular}{|c|c|c|c|c|c|}
\hline Disease / Age & Absolute & Y Loss & Relative & Y Loss & QALY \\
\hline & 30 & 60 & 30 & 60 & $\begin{array}{c}\text { CR } \\
\text { approach }\end{array}$ \\
\hline $\begin{array}{l}\text { Average QALY level for healthy } \\
\text { people }\end{array}$ & 0,684 & 0,698 & & & \\
\hline $\begin{array}{l}\text { Arms, legs, hands, feet, back, } \\
\text { or neck }\end{array}$ & 0,089 & 0,084 & 0,130 & 0,120 & 0,159 \\
\hline Difficulty in Seeing & 0,173 & 0,173 & 0,253 & 0,248 & 0,062 \\
\hline Difficulty in Hearing & 0,175 & 0,16 & 0,256 & 0,229 & 0,038 \\
\hline Skin conditions/allergies & 0,159 & 0,159 & 0,232 & 0,228 & 0,034 \\
\hline $\begin{array}{l}\text { Chest/breathing problems, } \\
\text { asthma, bronchitis }\end{array}$ & 0,07 & 0,082 & 0,102 & 0,117 & 0,143 \\
\hline $\begin{array}{l}\text { Heart/blood problems or blood } \\
\text { circulation problems }\end{array}$ & 0,101 & 0,058 & 0,148 & 0,083 & 0,125 \\
\hline Stomach/liver/kidneys & 0,115 & 0,063 & 0,168 & 0,090 & 0,149 \\
\hline Diabetes & 0,135 & 0,084 & 0,197 & 0,120 & 0,165 \\
\hline $\begin{array}{l}\text { Anxiety, depression or bad } \\
\text { nerves }\end{array}$ & 0,137 & 0,105 & 0,200 & 0,150 & 0,209 \\
\hline $\begin{array}{l}\text { Alcohol or drug related } \\
\text { problems }\end{array}$ & 0,128 & 0,123 & 0,187 & 0,176 & 0,232 \\
\hline Epilepsy & 0,09 & 0,085 & 0,132 & 0,122 & 0,159 \\
\hline $\begin{array}{l}\text { Migraine or frequent } \\
\text { headaches }\end{array}$ & 0,173 & 0,173 & 0,253 & 0,248 & 0,066 \\
\hline Other health problems & 0,125 & 0,1 & 0,183 & 0,143 & 0,193 \\
\hline
\end{tabular}

\footnotetext{
${ }^{2}$ The sample mean in 1996 for income is U.K. $£ 1834$ per month and approximately 10 years of education.
} 
The relative QALY loss for diabetes is 0,197 for a male of 30 years old, and 0.120 for one of 60 years old. The QALY weight for diabetes derived by CR approach is 0.165 .

Let us now look what are the averages for the British population, as represented by the waves 1996-8 in the BHPS. Here, we calculate for all respondents their expected $H S$ value and the corresponding QALY. Next, we compute the QALY for all the respondents under the hypothetical situation that none of the individuals suffer from any illness, i.e. if all the individuals were cured from these drawbacks. We call the first measure the actual QALY level and the second the cured QALY level. Then, we can define the QALY loss as the difference between the actual and the cured QALY. In table 3, we present the averages of the actual QALY levels and QALY losses for the total sample, over the sub - samples of males and females, and for three age brackets. The actual QALY level is for the whole population about 0,75 . The level falls with increasing age from 0,79 to 0.70 . Females have a lower QALY than males. The average QALY loss, caused by the illnesses, including multiple prevalence, is about 0,08 . Hence, the QALY level is reduced by more than $10 \%$.

In the rest of the table we look at the QALY loss caused by having one illness. For each illness, we present 3 rows. The first row shows the actual QALY, the second the QALY loss, and the third the corresponding sample frequencies. We see that the most frequently found illnesses is problems with 'arms, legs, hands, feet, back, or neck', viz. for $27 \%$ of the sample, followed by 'chest and breathing problems', and 'heart problems' and 'skin probelms'. The surprisingly large percentage of respondents with 'arms, legs, hands, feet, back, or neck problems' may be caused by the fact that it is a broad impediment definition that includes very different degrees of severity, which can not be distinguished in the BHPS. The overall QALY loss due to arms problems is 0.023 . However, if we restrict the loss to the actual sufferers it implies that the loss has to be multiplied for the sufferers by $1 / 0.27$. It follows that the loss for sufferers is about 0.11 . Similar calculations can be made for the other illnesses.

We can see in table 3 that the lower QALY for female respondents is especially due to the 'arms, legs, hands, feet, back, or neck problems', 'Anxiety, depression or bad nerves', and 'migraine or frequent headaches'. This result is a combination of different weights and different prevalence of the illness among the sub-samples. 
Table 3. QALY averages and losses in the population.

\begin{tabular}{|c|c|c|c|c|c|c|c|}
\hline & & Total & Male & Female & $<30$ & $30-65$ & $>65$ \\
\hline Actual QALY & & 0.7514 & 0.7633 & 0.7412 & 0.7879 & 0.7543 & 0.7040 \\
\hline QALY loss & & 0.0847 & 0.0719 & 0.0956 & 0.0456 & 0.0799 & 0.1393 \\
\hline \multicolumn{8}{|l|}{ One Illness } \\
\hline \multirow[t]{3}{*}{ Arms } & QALYUN & 0.8130 & 0.8145 & 0.8116 & 0.8250 & 0.8130 & 0.7995 \\
\hline & QALYWIN & 0.0231 & 0.0207 & 0.0252 & 0.0084 & 0.0213 & 0.0437 \\
\hline & $\%$ Prevalence & $27.32 \%$ & $24.33 \%$ & $29.87 \%$ & $9.63 \%$ & $24.71 \%$ & $52.99 \%$ \\
\hline \multirow[t]{3}{*}{ Sight } & QALYUN & 0.8346 & 0.8340 & 0.8352 & 0.8328 & 0.8333 & 0.8397 \\
\hline & QALYWIN & 0.0015 & 0.0013 & 0.0016 & 0.0006 & 0.0009 & 0.0035 \\
\hline & $\%$ Prevalence & $4.78 \%$ & $4.17 \%$ & $5.30 \%$ & $2.13 \%$ & $3.07 \%$ & $11.59 \%$ \\
\hline \multirow[t]{3}{*}{ Hearing } & QALYUN & 0.8347 & 0.8336 & 0.8356 & 0.8326 & 0.8331 & 0.8406 \\
\hline & QALYWIN & 0.0014 & 0.0016 & 0.0012 & 0.0009 & 0.0012 & 0.0026 \\
\hline & $\%$ Prevalence & $8.13 \%$ & $9.26 \%$ & $7.17 \%$ & $2.26 \%$ & $5.24 \%$ & $21.22 \%$ \\
\hline \multirow[t]{3}{*}{ Chest } & QALYUN & 0.8260 & 0.8255 & 0.8265 & 0.8255 & 0.8258 & 0.8271 \\
\hline & QALYWIN & 0.0101 & 0.0097 & 0.0104 & 0.0079 & 0.0085 & 0.0161 \\
\hline & $\%$ Prevalence & $13.44 \%$ & $12.91 \%$ & $13.89 \%$ & $13.12 \%$ & $11.20 \%$ & $18.85 \%$ \\
\hline \multirow[t]{3}{*}{ Skin } & QALYUN & 0.8341 & 0.8336 & 0.8344 & 0.8309 & 0.8323 & 0.8417 \\
\hline & QALYWIN & 0.0020 & 0.0016 & 0.0024 & 0.0025 & 0.0020 & 0.0015 \\
\hline & $\%$ Prevalence & $12.32 \%$ & $9.78 \%$ & $14.48 \%$ & $15.25 \%$ & $12.17 \%$ & $9.38 \%$ \\
\hline \multirow[t]{3}{*}{ Heart } & QALYUN & 0.8275 & 0.8274 & 0.8276 & 0.8309 & 0.8273 & 0.8243 \\
\hline & QALYWIN & 0.0086 & 0.0078 & 0.0092 & 0.0025 & 0.0070 & 0.0190 \\
\hline & $\%$ Prevalence & $14.18 \%$ & $12.93 \%$ & $15.24 \%$ & $2.27 \%$ & $9.72 \%$ & $37.53 \%$ \\
\hline \multirow[t]{3}{*}{ Stomach } & QALYUN & 0.8304 & 0.8301 & 0.8306 & 0.8297 & 0.8280 & 0.8364 \\
\hline & QALYWIN & 0.0057 & 0.0051 & 0.0063 & 0.0038 & 0.0062 & 0.0068 \\
\hline & $\%$ Prevalence & $7.34 \%$ & $6.46 \%$ & $8.09 \%$ & $2.93 \%$ & $7.14 \%$ & $12.73 \%$ \\
\hline \multirow[t]{3}{*}{ Diabetes } & QALYUN & 0.8339 & 0.8330 & 0.8347 & 0.8322 & 0.8325 & 0.8388 \\
\hline & QALYWIN & 0.0022 & 0.0023 & 0.0022 & 0.0012 & 0.0017 & 0.0044 \\
\hline & $\%$ Prevalence & $2.47 \%$ & $2.52 \%$ & $2.43 \%$ & $0.78 \%$ & $1.68 \%$ & $6.12 \%$ \\
\hline \multirow[t]{3}{*}{ Depress } & QALYUN & 0.8272 & 0.8294 & 0.8253 & 0.8271 & 0.8239 & 0.8349 \\
\hline & QALYWIN & 0.0089 & 0.0058 & 0.0115 & 0.0063 & 0.0104 & 0.0083 \\
\hline & $\%$ Prevalence & $7.50 \%$ & $4.85 \%$ & $9.75 \%$ & $4.39 \%$ & $8.59 \%$ & $8.49 \%$ \\
\hline \multirow[t]{3}{*}{ Alcohol\&Drugs } & QALYUN & 0.8355 & 0.8344 & 0.8365 & 0.8327 & 0.8336 & 0.8430 \\
\hline & QALYWIN & 0.0006 & 0.0009 & 0.0003 & 0.0007 & 0.0007 & 0.0002 \\
\hline & $\%$ Prevalence & $0.45 \%$ & $0.67 \%$ & $0.27 \%$ & $0.56 \%$ & $0.52 \%$ & $0.17 \%$ \\
\hline \multirow[t]{3}{*}{ Epilepsi } & QALYUN & 0.8354 & 0.8346 & 0.8361 & 0.8326 & 0.8335 & 0.8428 \\
\hline & QALYWIN & 0.0007 & 0.0006 & 0.0007 & 0.0008 & 0.0007 & 0.0004 \\
\hline & $\%$ Prevalence & $0.76 \%$ & $0.72 \%$ & $0.80 \%$ & $0.91 \%$ & $0.82 \%$ & $0.47 \%$ \\
\hline \multirow[t]{3}{*}{ Migraine } & QALYUN & 0.8332 & 0.8337 & 0.8328 & 0.8306 & 0.8309 & 0.8412 \\
\hline & QALYWIN & 0.0029 & 0.0015 & 0.0040 & 0.0028 & 0.0033 & 0.0020 \\
\hline & $\%$ Prevalence & $9.41 \%$ & $5.03 \%$ & $13.14 \%$ & $9.20 \%$ & $10.83 \%$ & $6.46 \%$ \\
\hline \multirow[t]{3}{*}{ Other } & QALYUN & 0.8308 & 0.8316 & 0.8301 & 0.8304 & 0.8288 & 0.8358 \\
\hline & QALYWIN & 0.0053 & 0.0037 & 0.0067 & 0.0030 & 0.0055 & 0.0074 \\
\hline & $\%$ Prevalence & $4.95 \%$ & $3.47 \%$ & $6.20 \%$ & $2.35 \%$ & $4.94 \%$ & $7.87 \%$ \\
\hline \multicolumn{2}{|c|}{ Number of Observations } & 29979 & 13779 & 16200 & 7670 & 16669 & 5640 \\
\hline
\end{tabular}




\section{Conclusions.}

In this paper we considered how we assign QALY losses to various impediments and illnesses. For that, we use individual self-ratings of health. The method we use is a refinement of the method originally devised by Cutler and Richardson (1997). The novelties of the paper are two. First, we exhaust all available information to transform the individual estimated responses $(H)$ into QALY values. Thus, we get a better insight into the non- linear relation between the cardinal QALY and the observed variable Health $(H)$, where Cutler and Robertson assume a linear relationship on the relevant range. It is obvious that the relationship becomes more accurate, the more response categories are distinguished in the Health Satisfaction question. Second, in our approach, the QALY weights depend on age. We introduce in the estimation interaction terms between illnesses and age. It is obvious that this can be extended to other characteristics such as gender and job situation

The QALY weights differentiated by age have a clear implication for the costeffectiveness analysis of therapies. In practice it implies that therapies on chronic diseases are more cost-effective for the demographic group with the higher QALY losses per year. This has an obvious ethical dimension.

The results of this paper show in our opinion that the method is operational to evaluate the health situations of populations and population subgroups. Other more problem oriented surveys are needed to trace the effect of illnesses and possible therapies in more detail. 


\section{References}

Cutler D, Richardson E., 1997. Measuring the health of the U.S. population. Brooking Papers: Microeconomics, p.217-271.

Deaton, A.S., and Paxson, C.H., 1998. Aging and Inequality in Income and Health. American Economic Review, 88: 248-253.

Dolan , P., 2000. The measurement of health-related quality of life. In: Culyer, A.J., Newhouse, J.P, (eds.). Handbook of Health Economics. V.1B. Elsevier, Amsterdam.

Friedman, M., 1957. A theory of the consumption function. Princeton University Press, Princeton, NJ.

Groot W., 2000. Adaptation and scale of reference bias in self-assessments of quality of life. Journal of Health Economics, 19: 403-420.

Kerkhofs M, Lindeboom M. 1995. Subjective health measures and state dependent reporting errors. Health Economics, 4: 221-235.

Mundlak, Y., 1978. On the Pooling of Time Series and Cross Section Data. Econometrica, 46: 69-85.

Praag, B.M.S. van, Frijters, P., and Ferrer-i-Carbonell, 2000. A structural model of well-being: with an application to German Data. Tinbergen Institute Discussion Paper TI 2000-053/3, the Netherlands.

Smith, J.P., 1999. Healthy bodies and thick wallets: the dual relation between health and economic status. Journal of Economic Perspectives, 13(2): 145-166.

Taylor, M.F. (ed). with J. Brice, N. Buck and E. Prentice-Lane, 1999. British Household Panel Survey User Manual Volume A: Introduction, Technical Report and Appendices. Colchester: University of Essex.

Torrance, G.W., 1986. Measurement of health state utilities for economic appraisal. A review. Journal of Health Economics, 5: 1-30. 


\section{IZA Discussion Papers}

\section{No Author(s)}

231

G. Saint-Paul

232

E. Bardasi

M. Francesconi

233

C. Dustmann

C. M. Schmidt

234 R. Rotte

M. Steininger

235 W. Schnedler

236 R. Hujer

M. Caliendo

237 S. Klasen

I. Woolard

238 R. Euwals

A. Börsch-Supan

A. Eymann

239 F. Andersson

K. A. Konrad

240

W. Koeniger

241

W. Koeniger

242
G. Faggio
J. Konings

243

E. Brainerd

244

S. M. Fuess, Jr. M. Millea
Titel

Area

Date

The Economics of Human Cloning

5

$12 / 00$

The Effect of Non-Standard Employment on

5

$12 / 00$

Mental Health in Britain

The Wage Performance of Immigrant Women:

Full-Time Jobs, Part-Time Jobs, and the Role of

Selection

Sozioökonomische Determinanten extremistischer 3

$12 / 00$

Wahlerfolge in Deutschland: Das Beispiel der Europawahlen 1994 und 1999

Who gets the Reward? An Empirical Exploration

of Bonus Pay and Task Characteristics

Evaluation of Active Labour Market Policy:

6

$12 / 00$

Methodological Concepts and Empirical

Estimates

Surviving Unemployment without State Support:

3

$12 / 00$

South Africa

The Saving Behaviour of Two Person House-

5

$12 / 00$

holds: Evidence from Dutch Panel Data

Human Capital Investment and Globalization in

5

01/01

Extortionary States

Labor and Financial Market Interactions: The the UK 1969-95

Trade, Labor Market Rigidities, and GovernmentFinanced Technological Change

$01 / 01$

Job Creation, Job Destruction and Employment

4

$01 / 01$

Growth in Transition Countries in the 90's

Economic Reform and Mortality in the Former

4

$01 / 01$ Soviet Union: A Study of the Suicide Epidemic in the 1990s

Pay and Productivity in a Corporatist Economy: Evidence from Austria 
The Optimal Level and Composition of Retirement Benefit Systems

250 T. J. Hatton

J. G. Williamson

Demographic and Economic Pressure on

Emigration out of Africa

01/01

251 R. Yemtsov

Labor Markets, Inequality and Poverty in Georgia

$01 / 01$

252 R. Yemtsov

Inequality and Income Distribution in Georgia

$01 / 01$

253 R. Yemtsov

Living Standards and Economic Vulnerability in Turkey between 1987 and 1994 
263 N. Datta Gupta

N. Smith

264

C. Dustmann

265

M. Rosholm

M. Svarer

266 C. Dustmann

O. Kirchkamp

267 A. Newell

268

A. Newell

B. Reilly

269

H. Buddelmeyer

270

B. Augurzky

C. M. Schmidt

271 B. Augurzky

C. M. Schmidt

272 C. Belzil

J. Hansen

273 G. Saint-Paul

274

P. J. Pedersen

N. Smith

275 G. S. Epstein

T. Lecker

276

B. Amable

D. Gatti
Children and Career Interruptions:

The Family Gap in Denmark

5

$02 / 01$

Return Migration, Wage Differentials, and the 1

$02 / 01$

Optimal Migration Duration

Structurally Dependent Competing Risks

$02 / 01$

The Optimal Migration Duration and Activity

$02 / 01$

Choice after Re-migration

The Distribution of Wages in Transition Countries

4

$03 / 01$

The Gender Pay Gap in the Transition from

4

03/01

Communism: Some Empirical Evidence

Re-employment Dynamics of Disabled Workers

3

03/01

The Evaluation of Community-Based

6

$03 / 01$

Interventions: A Monte Carlo Study

The Propensity Score: A Means to An End

6

03/01

Heterogeneous Returns to Human Capital and

5

03/01

Dynamic Self-Selection

Distribution and Growth in an Economy with

5

$03 / 01$ Limited Needs

Unemployment Traps: Do Financial Dis-

3

$03 / 01$

incentives Matter?

Multi-Generation Model of Immigrant Earnings

03/01

Theory and Application

The Impact of Product Market Competition on

5

03/01 Employment and Wages 

national Integration

klund

S. Vroman

283 M. Hagedorn
A. Kaul

V. Reinthaler

Welfare Analysis in a Schumpeterian Growth to Internal Promotion for Young U.S. Men and Women Living Arrangements 

and the Rising Returns to Skill: US and France 1964-2000

293 D. Cobb-Clark T. F. Crossley

294 Š. Jurajda

N. Smith

L. Husted

297 J. C. van Ours J. Veenman

P. Cahuc

E. Wasmer
Gender, Comparative Advantage and Labor Market Activity in Immigrant Families Insurance Compensation on the Labor Market Histories of Displaced Workers

Individual Pay and Outside Options:

Intergenerational Transmissions and the Schoolto-Work transition of $2^{\text {nd }}$ Generation Immigrants

The Educational Attainment of Second Generation 1 Immigrants in The Netherlands

Returns to Education and Wage Equations and Subjective Well-Being The Role of Social Work

Economic and Social Perspectives of Immigrant 06/01 Children in Germany 

H. Bonin
G. Abío
E. Berenguer
J. Gil
C. Patxot

G. A. Pfann

D. S. Hamermesh
2

06/01 Accounting Perspective on Fiscal Policy and Labour Market Trends in Spain

Downsizing

$1 / 5$

06/01

Two-Sided Learning, Labor Turnover and Worker 1 06/01 Displacement

06/01

On the Complementarity between Education and 5 Training in Europe

06/01

Earnings Inequality

5

Unemployment, Education and Earnings Growth 3

06/01

The Value of Pain Relief

5

06/01

The Subjective Costs of Health Losses due to

7

06/01 Chronic Diseases: An Alternative Model for Monetary Appraisal

Age-Differentiated QALY Losses

7

$06 / 01$ 